\title{
THE MOVEABLE HANDHOLD: A NEW PARADIGM TO STUDY VISUAL CONTRIBUTIONS TO THE CONTROL OF BALANCE-RECOVERY REACTIONS
}

(revised July 28, 2008)

\author{
Authors: Kenneth C. Cheng, $\mathrm{MASc}^{1,2}$, Sandra M. McKay, PhD ${ }^{1}$, Emily C. King, \\ BASc $^{1,3}$, James Y. Tung, MEng ${ }^{1,4,5}$, Tracy A. Lee, $\mathrm{MSc}^{1}$, Carol Y. Scovil, \\ $\mathrm{PhD}^{1}$, and Brian E. Maki, PhD, PEng ${ }^{1-3,5,6}$ \\ Affiliations: $\quad{ }^{1}$ Centre for Studies in Aging, Sunnybrook Health Sciences Centre (Toronto) \\ ${ }^{2}$ Institute of Medical Science, University of Toronto \\ ${ }^{3}$ Institute of Biomaterials and Biomedical Engineering, University of Toronto \\ ${ }^{4}$ Graduation Department of Rehabilitation Science, University of Toronto \\ ${ }^{5}$ Toronto Rehabilitation Institute \\ ${ }^{6}$ Department of Surgery, University of Toronto
}

Correspondence: B.E. Maki, PhD, PEng

Centre for Studies in Aging

Sunnybrook Health Sciences Centre

2075 Bayview Avenue, Toronto, Ontario, CANADA M4N 3M5

Phone: 416-480-6100 ext. $3513 \quad$ Fax: 416-480-5856

E-mail: brian.maki@sri.utoronto.ca

Keywords: $\quad$ Balance reactions; grasping; reaching; vision; visual attention 
Running head: Moveable handholds and balance reactions 


\section{ABSTRACT}

Balance-recovery reactions that involve rapid step or reach-to-grasp movements are

3 prevalent and functionally important responses to instability. Successful use of these reactions to

4 recover balance in daily life requires a capacity to modulate the reaction to deal with the continual

5 variation in environmental constraints that occurs as the person moves, i.e. location of objects

6 that can obstruct limb movements or serve as handholds to grasp. The most direct approach to

7 study this involves applying balance perturbations as subjects move within a visually-complex

8 environment; however, this approach does not allow precise control over kinematic variables or

9 visual inputs, and is susceptible to strong learning effects. We have therefore developed an

10 alternate approach, wherein the subject is stationary and the relative motion between subject and

11 constraints that normally occurs as a result of ambulation is instead introduced via movement of

12 surrounding obstacles or handholds. We previously developed a motor-driven "obstacle-mover"

13 to manipulate constraints on step reactions, and now describe an analogous approach to study

14 reach-to-grasp reactions, using a motor-driven "handhold-mover". We anticipate that this

15 paradigm will provide new opportunities to probe CNS control of upright stance, by providing a

16 sensitive indicator of limitations in the neuromusculoskeletal systems. It can also be used to test

17 perturbation-evoked reactions in seated subjects, thereby allowing testing or training of persons

18 who are unable to stand and use of techniques (e.g. TMS, EEG) that can be difficult to perform in 19 free-standing subjects. 


\section{INTRODUCTION}

Balance-recovery reactions that alter the base-of-support, via rapid step or reach-to-grasp limb movements, play a crucial role in preventing falls [1]. However, successful use of these "change-in-support" reactions, in daily life, is likely to depend heavily on the ability to modulate the reaction to deal with the continual variation in environmental constraints that occurs as the person moves, i.e. location of objects that can obstruct limb movements or serve as handholds to grasp. There is a need to understand how the central nervous system (CNS) acquires the visuospatial

8 information needed to guide step and reach-to-grasp reactions amid changing environmental

9 constraints; however, research in this area has been hampered by methodological difficulties.

\section{METHODOLOGICAL ISSUES}

The most direct approach is to apply a balance perturbation as the subject moves within

12 the environment, and record the gaze behaviour that occurs before and after perturbation-onset

13 (PO). For example, a large motion-platform can be used to apply the perturbation, while providing

14 a visually-complex "real-life" environment with constraints on foot placement (clutter on floor, 15 stairs, etc.) as well as potential handholds to grasp (handrails, furniture, etc.) [2,3]. While this 16 approach can provide invaluable information regarding natural behaviour, there are a number of 17 practical limitations: 1) variation in gait precludes precise control over the position and motion of 18 the body, in relation to the constraints, at PO; 2) this variation also precludes precise control of 19 central and peripheral visual inputs; 3) subjects are likely to learn proactive strategies after a small 20 number of trials (e.g. grasp handholds prior to $\mathrm{PO}$ ). The latter limitation may be prohibitive in 21 studies requiring multiple within-subject assessments, e.g. before and after balance training.

To avoid these methodological problems, we have developed an alternate approach to 23 introduce spatio-temporal variation in environmental constraints prior to PO. Here, the subject is 24 stationary and the relative motion between subject and constraints that normally occurs as a 25 result of ambulation is instead introduced via movement of surrounding obstacles or handholds. 
1 Previously, we developed a motor-driven system to manipulate constraints on step reactions by

2 varying the location of obstacles surrounding the subject [4]. We now describe an analogous

3 approach to study reach-to-grasp reactions, using a motor-driven "handhold-mover" (HHM). The

$4 \mathrm{HHM}$ can be used to reposition the handhold before PO or after PO (e.g. during the reaching

5 phase of the reaction).

Ability to study reach-to-grasp reactions is important for several reasons. Because these reactions are functionally important in preventing falls, clinicians need to understand effects of aging, injury and disease [1]. Studying reach-to-grasp reactions also presents unique opportunities to probe CNS control of balance. Such reactions are likely to be one of the most challenging aspects of balance control, particularly when graspable objects are restricted in size

11 or location, or the opportunity to view them is limited. Thus, testing these reactions can provide a 12 sensitive indicator of limitations in the neuromusculoskeletal systems. This also provides 13 opportunities to assess CNS control of balance in seated subjects [5]. It then becomes possible 14 to test or train patients who are unable to stand (e.g. stroke), control confounding factors (e.g. fear 15 of falling) and use techniques (e.g. TMS, EEG) that can be difficult to perform in free-standing 16 subjects [2].

\section{DESCRIPTION OF THE HANDHOLD MOVER}

Our HHM (Figure 1; Table 1) is mounted on a motion-platform, but can be used with any type of balance-perturbation system. A linear-actuator (ball screw and stepper motor) provides accurate control of the handhold motion and end-point locations. The range of motion (800mm)

21 was selected to allow the handhold to move close to the subject when fully-deployed and out of 22 grasping range when fully-retracted. Structural components were designed to withstand the 23 substantial loading that can occur when using a handrail (up to 60\% of bodyweight [6]).

24 Ball-bushing rails are used to withstand orthogonal loads, and a brake prevents the motor from 25 being "back-driven" by axial loads. Potential auditory or vibration cues (transmitted through the 
1 floor) are minimized by using gradual acceleration/deceleration profiles. Auditory cues can also

2 be masked by playing pre-recorded HHM sounds through headphones. A safety harness

3 restrains subjects from moving into the handhold path-of-motion, and an "interlock" shuts down

4 the HHM if motion-platform force-plates indicate that someone may be standing in its path (Figure $52)$.

6

11 a computer screen located directly ahead, at a height that requires

12 head-orientation/gaze-direction similar to that occurring during ambulatory scanning of the travel

13 path [7]. With the subject required to direct gaze at the computer screen, the final locations of the

14 handhold correspond to specific visual angles in the peripheral field (see Figure 1B). Large foam

15 blocks, placed around the feet, prevent stepping and force reliance on reach-to-grasp reactions,

16 which are characterised using motion-analysis and EMG systems. An eye-tracker is used to

17 determine if the subject maintained fixation on the computer screen, or needed to direct gaze at 18 the handhold. For comparative purposes, subjects also perform trials where they maintain visual 19 fixation of the handhold, as it moves.

\section{OTHER POTENTIAL APPLICATIONS}

Many variations of the protocol are possible. For example, contact-lenses could be used to occlude specific regions of the visual field [8], liquid-crystal goggles could be used to occlude vision during specific time intervals of interest [9], and the capacity for on-line control could be probed by programming the handhold to move after initiation of the arm reaction. Potential 
1 applications range from studies of fundamental motor-control mechanisms to evaluation of clinical

2 interventions, such as the "visual-training" programs we are currently studying [10].

3 


\section{ACKNOWLEDGMENTS}

This study was funded by grant \#MOP-13355 from the Canadian Institutes of Health

3 Research (ClHR). K.C.C. held scholarships from the Ontario Graduate Scholarships in Science \&

4 Technology program, University of Toronto [Institute of Biomaterial and Biomedical Engineering

5 (IBBME) and Vision Science Research Program (VSRP)] and Toronto Rehabilitation Institute

6 (TRI). S.M.M. held postdoctoral awards from the Ontario Neurotrauma Foundation (ONF) and

7 University of Toronto [Health Care, Technology and Place Program (HCTP)]. E.C.K. held

8 scholarships from the CIHR, University of Toronto (IBBME and VSRP) and TRI. J.Y.T. held

9 scholarships from the Natural Sciences and Engineering Research Council of Canada, University

10 of Toronto (HCTP) and TRI. C.Y.S. held a postdoctoral award from the ONF. Assistance

11 provided by Amy Peters and Aaron Marquis is gratefully acknowledged.

The authors declare that they have no conflicts of interest. 
REFERENCES

2 [1] Maki BE, Mcllroy WE. Change-in-support balance reactions in older persons: an emerging

[2] Maki BE, Mcllroy WE. Cognitive demands and cortical control of human balance-recovery reactions. J Neural Transm 2007;114(10):1279-96.

[3] Scovil CY, Corbeil P, Lee TA, et al. A novel handrail cueing system to prevent falls in older

[4] Zettel JL, Scovil CY, Mcllroy WE, et al. Gaze behavior governing balance recovery in an

[5] Gage WH, Zabjek KF, Hill SW, et al. Parallels in control of voluntary and perturbation-evoked reach-to-grasp movements: EMG and kinematics. Exp Brain Res 2007;181(4):627-37.

13 [6] Maki BE, Perry SD, Mcllroy WE. Efficacy of handrails in preventing stairway falls: a new experimental approach. Safety Science 1998;28(3):189-206.

[7] Marigold DS, Patla AE. Gaze fixation patterns for negotiating complex ground terrain. Neuroscience 2007;114(1):302-13.

17 [8] Sivak B, MacKenzie CL. Integration of visual information and motor output in reaching and

[10] McKay SM, Cheng KC, King EC, et al. Visual processing and postural reactions: development and pilot testing of a "visual training" program to improve balance control and prevent falls in older adults. In: Proceedings of the 4th International Conference on Aging, Disability, and Independence, St Petersburg, FL; 2008. 
Table 1: Technical specifications of the handhold-mover (HHM)

\begin{tabular}{|c|c|c|c|}
\hline \multicolumn{2}{|r|}{ FEATURE } & SPECIFICATION & NOTES \\
\hline \multirow{4}{*}{$\stackrel{0}{0}_{\substack{0 \\
0}}^{0}$} & $\begin{array}{l}\text { Axis and } \\
\text { range of } \\
\text { motion }\end{array}$ & $\begin{array}{l}800 m m \\
\text { Transverse axis in } \\
\text { front of subject, on } \\
\text { the right-hand side }\end{array}$ & $\begin{array}{l}\text { Fully-deployed and fully-retracted (out-of-reach) positions are } 50 \mathrm{~mm} \\
\text { and } 850 \mathrm{~mm} \text { to right of subject's midline, respectively.* } \\
\text { Distance between HHM axis and back of heels is equal to } 25 \% \text { of body } \\
\text { height. }\end{array}$ \\
\hline & End points & $\begin{array}{l}\text { Any position } \\
\text { within range of } \\
\text { motion }\end{array}$ & $\begin{array}{l}\text { Can be specified in absolute position }(\mathrm{mm}) \text { or in equivalent visual } \\
\text { angle (see Fig. 1B) }\end{array}$ \\
\hline & Speed & $480 \mathrm{~mm} / \mathrm{s}$ (max) & $\begin{array}{l}\text { Allows full range of motion to be traversed in } 2 \text { s; slower speeds can } \\
\text { also be programmed. } \\
\text { Maximum speed was limited to this value for safety. }\end{array}$ \\
\hline & $\begin{array}{l}\text { Acceleration/ } \\
\text { deceleration }\end{array}$ & $784 \mathrm{~mm} / \mathrm{s}(\max )$ & $\begin{array}{l}\text { Limited to avoid sudden jerks that could provide vibrational cues } \\
\text { (transmitted via motion-platform floor). }\end{array}$ \\
\hline \multirow{2}{*}{ 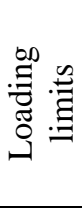 } & Vertical & $120 k g-f(545 N)$ & $\begin{array}{l}60 \% \text { body weight }(\text { see }[6]) \times 100 \mathrm{~kg}\left(95^{\text {th }} \text { percentile male weight }\right) \times 2.0 \\
(\text { safety factor })\end{array}$ \\
\hline & Horizontal & $90 \mathrm{~kg}-f(410 N)$ & $\begin{array}{l}45 \% \text { body weight }(\text { see }[6]) \times 100 \mathrm{~kg}\left(95^{\text {th }} \text { percentile male weight }\right) \times 2.0 \\
(\text { safety factor }) \\
\text { Note: horizontal }=\text { parallel or normal to axis of motion }\end{array}$ \\
\hline \multirow{6}{*}{ 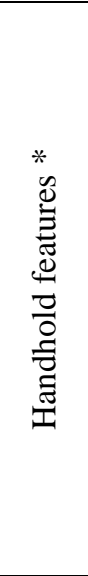 } & Height & $\begin{array}{l}\text { Adjustable: } \\
\text { 915mm - } \\
1120 \mathrm{~mm}\end{array}$ & $\begin{array}{l}\text { Min: } 60 \% \text { body height } \times 1520 \mathrm{~mm}\left(5^{\text {th }} \text { percentile female }\right) \\
\text { Max: } 60 \% \text { body height } \times 1880 \mathrm{~mm}\left(95^{\text {th }} \text { percentile male }\right)\end{array}$ \\
\hline & Shape & Cylindrical & \multirow{2}{*}{$\begin{array}{l}\text { Cylindrical shape and diameter of } 32-44 \mathrm{~mm} \text { are recommended for stair } \\
\text { handrails (see [6]). }\end{array}$} \\
\hline & Diameter & $32 m m$ & \\
\hline & Length & $190 \mathrm{~mm}$ & $95^{\text {th }}$ percentile male hand breadth $=102 \mathrm{~mm}$ \\
\hline & Orientation & Transverse axis & \\
\hline & Sensors & $\begin{array}{l}3 \text { force-sensing } \\
\text { resistor strips } \\
\text { (FSR-408) }\end{array}$ & $\begin{array}{l}\text { Manufacturer: Interlink Electronics, Inc.; Camarillo, CA. } \\
\text { The FSR strips, taped along the length of the handhold (top, back and } \\
\text { front surfaces), currently provide contact signals, but could also be } \\
\text { calibrated to provide contact-force information. The handhold could be } \\
\text { mounted on a multi-axis load cell if more detailed information about } \\
\text { the applied forces and moments is required. }\end{array}$ \\
\hline \multirow{4}{*}{ 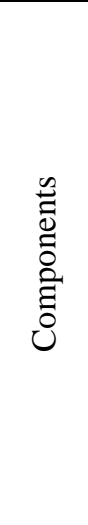 } & $\begin{array}{l}\text { Linear } \\
\text { actuator }\end{array}$ & $\begin{array}{l}\text { Ball-screw } \\
\text { linear-actuator } \\
\text { (ROBO cylinder } \\
\text { RCP2-SA7) }\end{array}$ & $\begin{array}{l}\text { Manufacturer: Intelligent Actuator Inc.; Torrance, CA } \\
\text { Built-in mechanical brake is activated whenever the motor is not } \\
\text { running. Handhold position (resolution } 0.02 \mathrm{~mm}) \text { is defined by the } \\
\text { screw lead }(16 \mathrm{~mm} / \mathrm{rev}) \text { and stepper-motor encoding (800pulses } / \mathrm{rev}) \text {. }\end{array}$ \\
\hline & $\begin{array}{l}\text { Linear } \\
\text { bushings }\end{array}$ & $\begin{array}{l}4 \text { ball bushings } \\
\text { (model } \\
\text { SSUPBO12) }\end{array}$ & Manufacturer: Thomson, Danaher Motion; Washington, DC \\
\hline & Linear guides & $\begin{array}{l}2 \text { parallel } 3 / 4 ” \\
\text { class-L steel } \\
\text { RoundRail }\end{array}$ & Manufacturer: Thomson, Danaher Motion; Washington, DC \\
\hline & Structure & $\begin{array}{l}\text { Aluminum } \\
\text { extrusions (model } \\
\text { 15EX1515) }\end{array}$ & $\begin{array}{l}\text { Manufacturer: Faztek LLC; Fort Wayne, IN } \\
\text { Extrusions are strong and lightweight; joints are reinforced by steel } \\
\text { plates and angle brackets. }\end{array}$ \\
\hline
\end{tabular}

*NOTE: The specifications for the HHM axis of motion and handhold features correspond to the prototype system in Figure 1. Other configurations (including the use of multiple HHM's) may be preferred in other studies. It may also be of interest to vary handhold shape, size and/or orientation, e.g. to study the effects on the prehensile phase of the reach-to-grasp reaction. 

FIGURE CAPTIONS

Figure 1: Schematic drawings and photographs showing the handhold mover (HHM) mounted on a large $(2 m \times 2 m)$ motion-platform (capable of moving in any horizontal direction), as well as the location of the computer monitor used to provide a visual target (and any other displays required in dual-task studies where the subject performs an ongoing cognitive task): A. isometric view; B. top view; C. photograph of $\mathrm{HHM}$ at the fully-retracted (out-of-reach) position (850mm from midline of subject); and D. photograph of HHM at the fully-deployed (in-reach) position (50mm from midline); E. photograph of a subject grasping the $\mathrm{HHM}$ at the fully-deployed position. B shows the handhold travel path (black horizontal line), and three end positions that correspond to visual angles of $15^{\circ}, 25^{\circ}$ and $35^{\circ}$ (dotted lines) when gaze is directed straight

11 ahead at the computer monitor (visual angle of $0^{\circ}$; black vertical line).

Figure 2: Flowchart for the custom-written LabVIEW ${ }^{\mathrm{TM}}$ program (National Instruments 13 Corp; Austin, TX) used to control the handhold-mover (HHM). The experimenter controls the 14 HHM using a line-by-line text file detailing, for each trial, the pseudorandom sequence of 15 intermittent handhold movements to be completed prior to stopping at the desired final position ${ }^{1}$.

16 The text file indicates the end point of each movement (specified as either an absolute position or 17 a visual angle), along with the "dwell time" (i.e. the time to wait before initiating the next handhold 18 movement). The platform motion is triggered, after an optional (random) time delay, once the 19 handhold has completed its sequence of movements. During the interval prior to onset of 20 platform motion, the program monitors the vertical loading of the three force-plates embedded in 21 the motion-platform surface, and aborts the trial (i.e. stops the handhold movement and prevents 22 the triggering of platform motion) if the force-plate signals indicate that the subject (or any other 23 person) may have moved into an area where the moving handhold could strike the body ${ }^{2}$. 


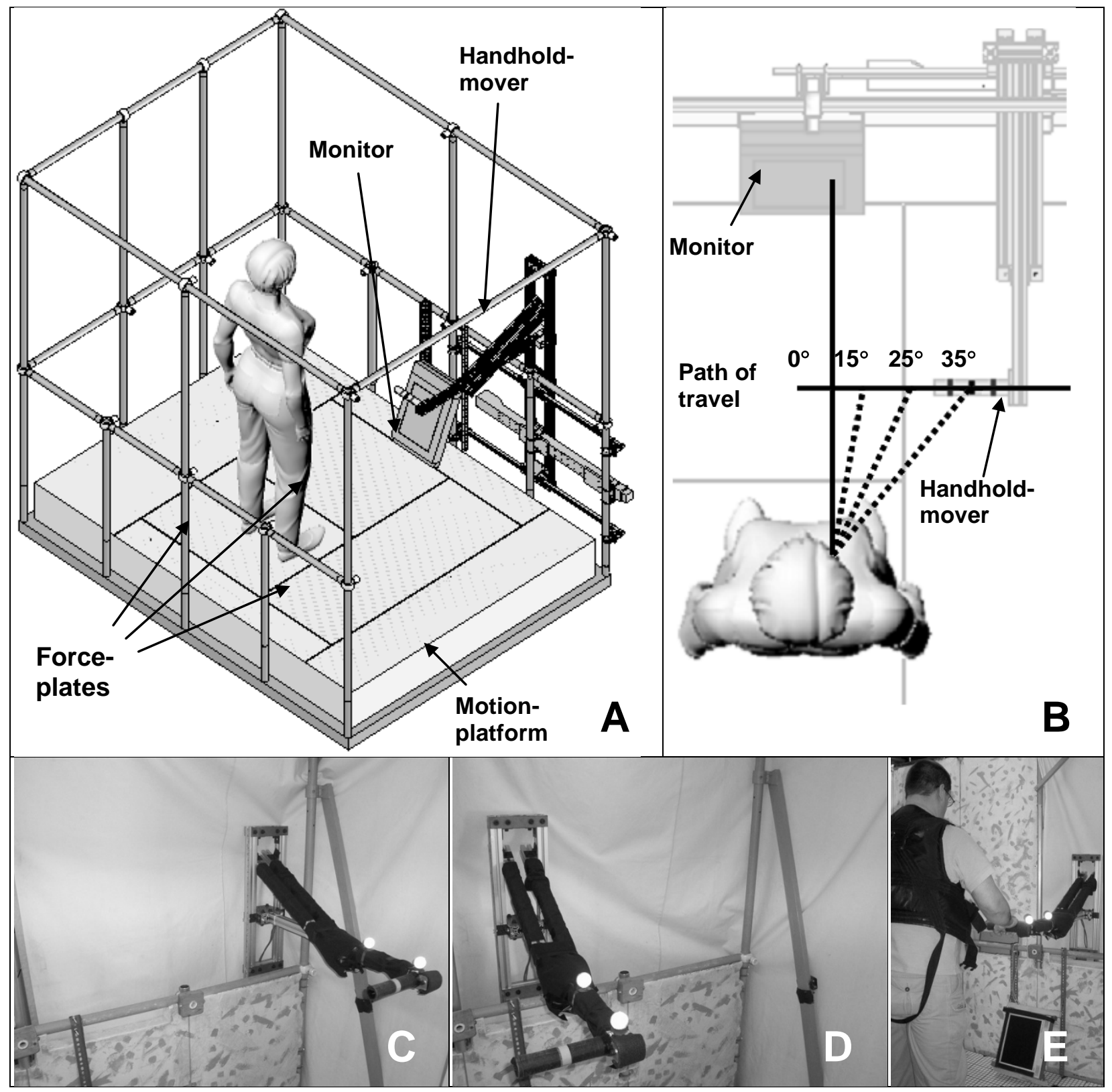


Figure 1

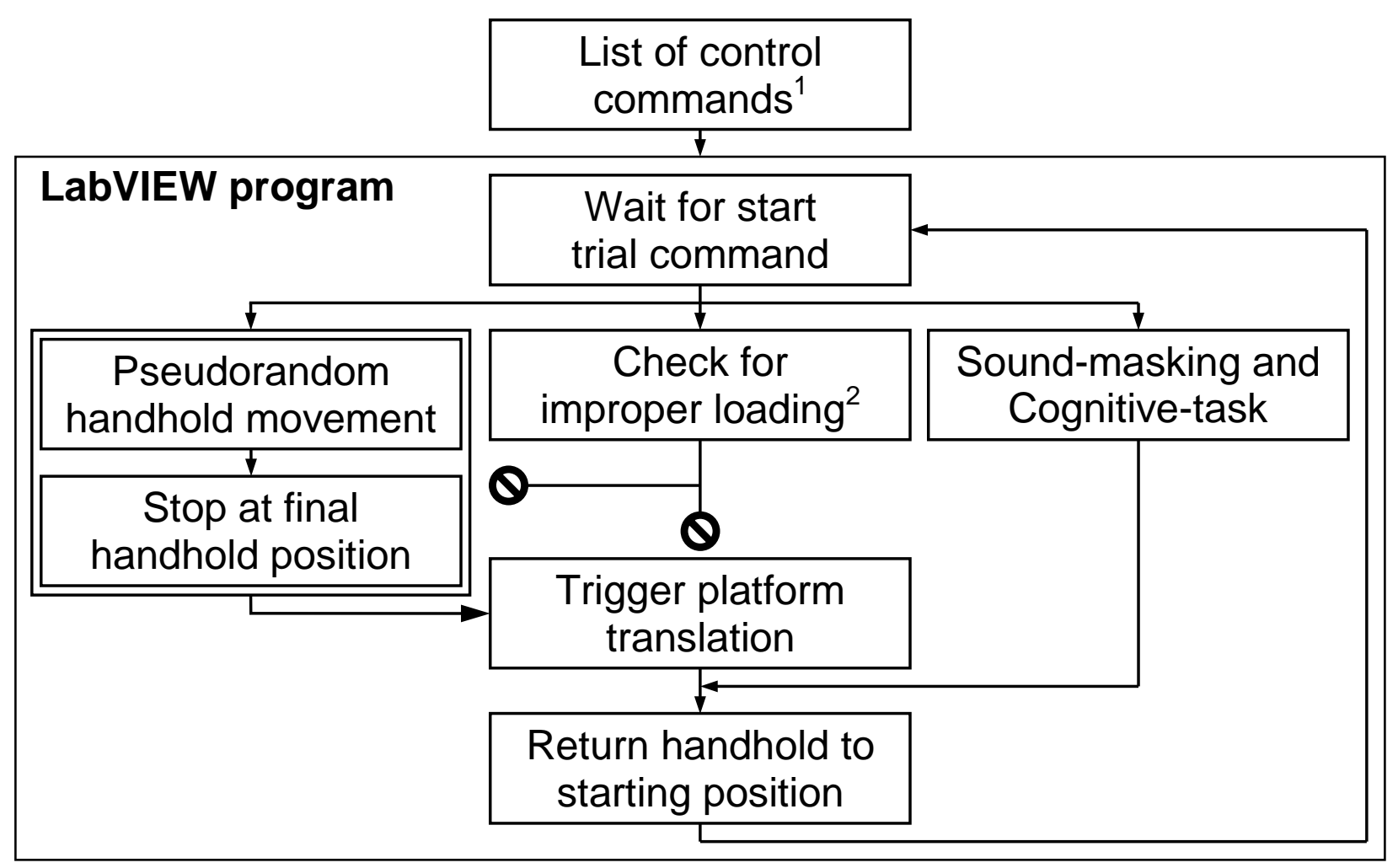

Figure 2 